\title{
Fabrication and characterization of wire-like $\mathrm{SnO}_{2}$
}

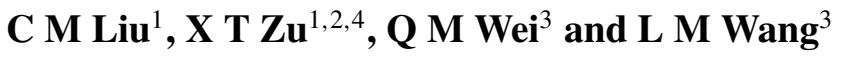 \\ ${ }^{1}$ Department of Applied Physics, University of Electronic Science and Technology of China, \\ Chengdu, 610054, People's Republic of China \\ ${ }^{2}$ International Center for Material Physics, Chinese Academy of Sciences, Shenyang \\ 110015, People's Republic of China \\ ${ }^{3}$ Department of Nuclear Engineering and Radiological Sciences, University of Michigan, \\ Ann Arbor, MI 48109-2104, USA \\ E-mail: xiaotaozu@yahoo.com and cmliu@uestc.edu.cn
}

Received 4 March 2006, in final form 24 April 2006

Published 2 June 2006

Online at stacks.iop.org/JPhysD/39/2494

\begin{abstract}
Wire-like $\mathrm{SnO}_{2}$ is fabricated by the wet chemical method. X-ray diffraction measurements show that the obtained samples have rutile-type structure. Electron transmission microscopy experiments illustrate that the wire-like $\mathrm{SnO}_{2}$ ranged from 10 to $50 \mathrm{~nm}$ in width and several microns $(\mu \mathrm{m})$ in length. The high-resolution TEM indicates that $\mathrm{SnO}_{2}$ wires are single crystals. The possible growth mechanism is proposed, and it is found that polyethylene glycol plays an important role in obtaining the wire-like and nano-rods morphology of $\mathrm{SnO}_{2}$. The band gap is determined to be $3.56 \mathrm{eV}$. Two photoluminescence peaks located at 389 and $470 \mathrm{~nm}$ are observed. Our fabrication method promises a simple way of synthesizing wire-like $\mathrm{SnO}_{2}$ at a low temperature of $350^{\circ} \mathrm{C}$.
\end{abstract}

\section{Introduction}

Rutile-type $\mathrm{SnO}_{2}$ is an important semiconductor with a wide band gap. It is widely used as gas sensor [1] and transparent conducting electrode [2]. Recently, more and more attention has been paid to the fabrication and characterization of onedimensional (1D) $\mathrm{SnO}_{2}$, such as nano-wires, nano-rods, nanobelts and nano-tubes [3-7]. The $1 \mathrm{D} \mathrm{SnO}_{2}$ is promising for nano-structured elements. Usually, $1 \mathrm{D} \mathrm{SnO}_{2}$ is fabricated using the vapour-liquid-solid (V-L-S) process, by thermal evaporation of pure $\mathrm{Sn}, \mathrm{SnO}, \mathrm{SnO}_{2}$ powders or their mixture [3-8]. Zhang et al [9] presented a different way of synthesis of $\mathrm{SnO}_{2}$ nano-belts by thermal evaporation of $\mathrm{SnCl}_{2}$ at a temperature of $900^{\circ} \mathrm{C}$. As indicated by Zhang et al [9], the presently reported routes require very high temperature or high post temperature treatment (above $800^{\circ} \mathrm{C}$ ). However, using polyethylene glycol (PEG) as a morphology-director, vanadium oxide nano-belts were obtained by hydrothermal treatment of $\mathrm{NH}_{4} \mathrm{VO}_{3}$ at $180^{\circ} \mathrm{C}$ [10]. In this paper, we illustrate a simple way using PEG as morphology-director to obtain wire-like $\mathrm{SnO}_{2}$ at a low temperature of $350^{\circ} \mathrm{C}$.

\footnotetext{
4 Author to whom any correspondence should be addressed.
}

\section{Experiments}

In a typical synthesis route, $0.05 \mathrm{~mol}$ tin chloride (hydrous $\mathrm{SnCl}_{4} \cdot 5 \mathrm{H}_{2} \mathrm{O}$ (A.R.)) is dissolved in $96 \mathrm{ml}$ distilled water firstly ( $\mathrm{pH}$ is adjusted by citric acid to 1.5-2). The solution is stirred and heated up from room temperature to $50^{\circ} \mathrm{C}$. When the

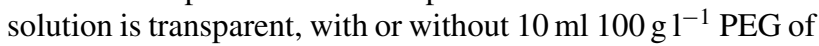
average molecular weight, $6000 \mathrm{~g} \mathrm{~mol}^{-1}$ (PEG6000) solution is added secondly. Then $20 \mathrm{ml}$ aqueous ammonia solution (25-28\% weight) is added to the above solution dropwise. The dropping rate must be well controlled for the chemical homogeneity. The dropping rate is about $0.7 \mathrm{ml} \mathrm{min}{ }^{-1}$. The reaction temperature is about $50^{\circ} \mathrm{C}$. The solution is vigorous stirred during the reaction. The final $\mathrm{pH}$ is $7-8$. The resulting gel is kept at $50^{\circ} \mathrm{C}$ for $2 \mathrm{~h}$. After this, it is preserved at room temperature for $11 \mathrm{~h}$, collected, washed with distilled water, and then dried at $100^{\circ} \mathrm{C}$ for several hours. Finally, heating treatments are conducted at $350^{\circ} \mathrm{C}$ in air for $1 \mathrm{~h}$. One sample without PEG added and two samples with PEG added in the synthesis routes are investigated in this study.

The crystalline structure of the material is analysed by x-ray diffraction (XRD) using a Rigaku D/max-2400 diffractometer with curved crystal monochromator and $\mathrm{Cu}-$ $\mathrm{K} \alpha$ radiation $(=0.154056 \mathrm{~nm})$ operated at $40 \mathrm{KV}$ and $60 \mathrm{~mA}$. 
The samples' stoichiometry is measured by a KRATOS X SAM 800 x-ray photoelectron spectroscope (XPS). The feature micrographs are obtained using a JEM 2010F transmission electron microscope (TEM). After the sample is well dispersed in distilled water suspension using a supersonic disperser, the absorption spectra of the samples are measured on a Shimadzu UV-2500 UV-Visible spectrophotometer. The photoluminescence (PL) spectra are measured with a Shimadzu RF-5301PC spectrofluorophotometer.

\section{Results and discussions}

Figure 1 shows the XRD pattern of $\mathrm{SnO}_{2}$ obtained with PEG6000 added in the fabrication routes. The diffraction index is indicated in the figure. As seen in figure 1, XRD measurement reveals that the structure of the samples is rutiletype cassiterite (tetragonal) phase of $\mathrm{SnO}_{2}$. No other impurity phase is detected in XRD measurements.

Like those reported in [3,4], the two obtained samples with PEG6000 added in the fabrication routes are rich in

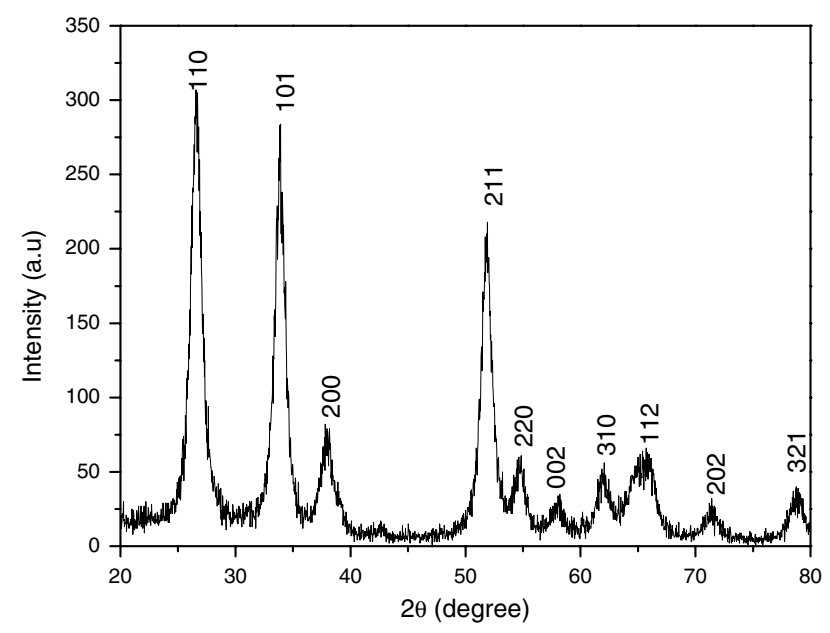

Figure 1. The XRD pattern of $\mathrm{SnO}_{2}$ with PEG6000 added in the fabrication routes. morphologies: there are spherical granules, nano-rods and wire-like structures. There are at least $10 \%$ fractions of the TEM graphs exhibiting the wire-like structures. The morphologies of the $\mathrm{SnO}_{2}$ sample with PEG6000 added in the fabrication routes are shown in figures $2(a)$ and $(b)$. The morphology in figure $2(b)$ is the most prevalent pattern of the TEM graphs. There are about $90 \%$ of the TEM patterns representing this morphology in figure $2(b)$. As seen in figure 2(a), the wire-like $\mathrm{SnO}_{2}$ has a width ranging from 10 to $50 \mathrm{~nm}$ and lenght of several microns. Some of the wires are uniform in length, while others have many branches. Furthermore, the wire-like $\mathrm{SnO}_{2}$ connects with each other and forms a dentritic structure. As indicated by figure 2(b), besides some spherical nano-particles, there are a large number of nano-rods granules. The nano-rods have a length of about $50-400 \mathrm{~nm}$, and a width of about $10-50 \mathrm{~nm}$. The length of nano-rods may be depends on the chain length of the PEG6000. The morphology of the sample without PEG6000 added in the synthesis routes is shown in figure 3 . There is no wire-like structure or nano-rods in figure 3 , and the grain size is about $50 \mathrm{~nm}$. The difference in characteristics shown between figures 2 and 3 implies that PEG6000 plays a crucial role in determining the morphology of $\mathrm{SnO}_{2}$. In the report on the synthesis of vanadium oxide nano-belts [10], the PEG polymer acts as heterogeneous nucleation sites for $\mathrm{V}_{2} \mathrm{O}_{5} \cdot \mathrm{nH}_{2} \mathrm{O}$ due to the fact that lower activation energy is required for heterogeneous nucleation at the polymer/water interface. And, the more or less extended polymer chain of PEG serves as the template directing the assembly and 1D growth of vanadium oxide to form belt-like nano-structures. In the formation of $\mathrm{ZnO}$ nano-rods [11], it seems that PEG has special interaction with some facets of $\mathrm{ZnO}$. PEG seems to have strong interaction with the side planes of the hexagonal prismatic $\mathrm{ZnO}$ (which are $\{100\}$ facets) and relatively weak interaction with the end planes (bounded by $\{001\}$ facets). This difference will cause the change of the relative growth rate of different facets, which causes $\mathrm{ZnO}$ to grow fast along the [001] direction. Ma et al [12] indicated that the more or less extended order of PEG polymer chain could provide a new sort of organization to metal atoms along the polymer

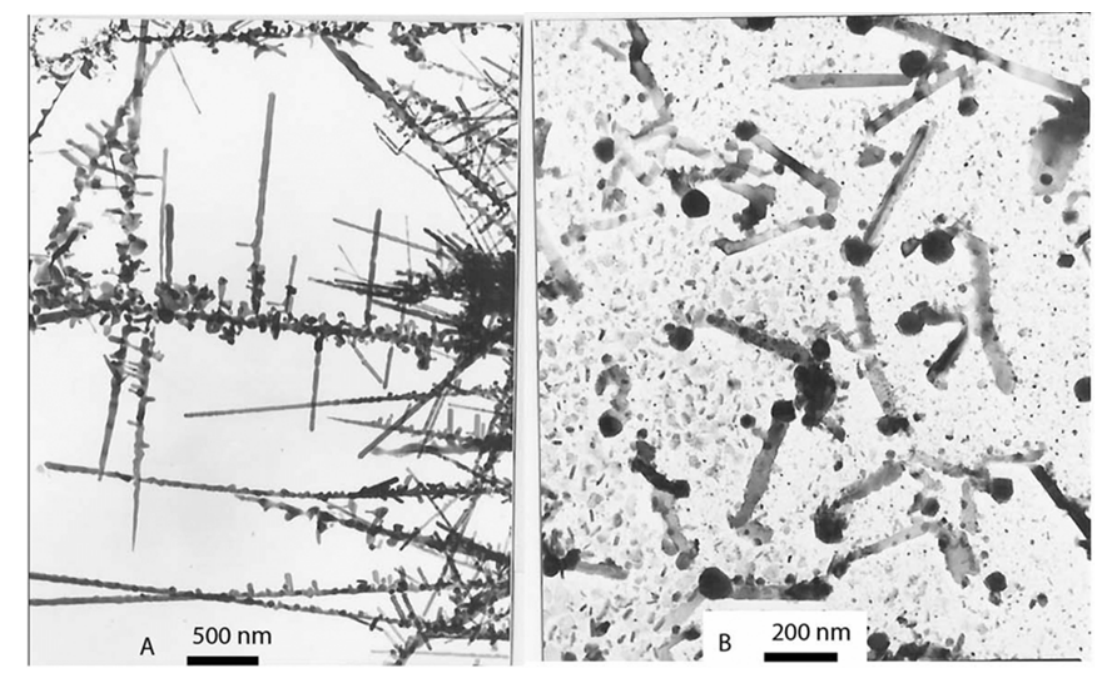

Figure 2. The TEM morphology of $\mathrm{SnO}_{2}$ with PEG6000 added in the fabrication routes: $(a)$ nano-wire like structures and $(b)$ nano-rods and spherical particles. 
backbone, which affords the diverse assembling ways for the $1 \mathrm{D}$ growth of the final products. The chain of every PEG may be extends and interacts with each other in an end-to-end way when the amount of PEG is sufficient and thus can form 1D further longer chain. Liu et al [13] showed that in the presence of alkalescence, $\mathrm{Zn}^{2+}$ can link with $\mathrm{O}$ atom in the chain of $\mathrm{C}-\mathrm{O}-\mathrm{C}$, which induced the change of the nucleation energy and led to the yield of $\mathrm{ZnO}$ seed crystal along the direction of the chain of PEG by the reaction between $\mathrm{Zn}\left(\mathrm{NH}_{3}\right)_{4}^{2+}$ and $\mathrm{OH}^{-} . \mathrm{Zn}\left(\mathrm{NH}_{3}\right)_{4}^{2+}$ is the reaction results of $\mathrm{Zn}\left(\mathrm{NO}_{3}\right)_{2} \cdot 6 \mathrm{H}_{2} \mathrm{O}$ and $\mathrm{NH}_{4} \cdot \mathrm{H}_{2} \mathrm{O}\left(\mathrm{Zn}^{2+}+4 \mathrm{NH}_{3} \rightarrow \mathrm{Zn}\left(\mathrm{NH}_{3}\right)_{4}^{2+}\right)$. As far as our case is concerned, the role played by ammonia may be similar to that played by $\mathrm{NH}_{4} \cdot \mathrm{H}_{2} \mathrm{O}$ in [13]. Like that presented by Liu et al [13], we suppose that $\mathrm{Sn}^{4+}$ can link with $\mathrm{O}$ atom in the chain of $\mathrm{C}-\mathrm{O}-\mathrm{C}$, which induced the change of the nucleation energy and led to the yield of $\mathrm{SnO}_{2}$ seed crystal along the direction of the chain of PEG. After heat treatment, the wirelike structure and nano-rods of $\mathrm{SnO}_{2}$ are formed. On the other hand, PEG may have special interaction with some facets of $\mathrm{SnO}_{2}$, which is similar to that proposed by [11]. Thus, the

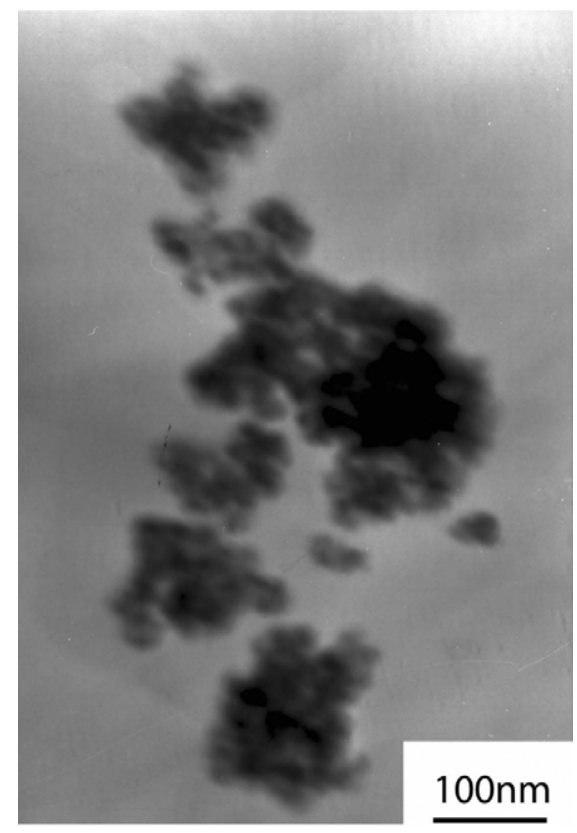

Figure 3. The TEM morphology of $\mathrm{SnO}_{2}$ without PEG6000 added in the fabrication routes. soft-template function of PEG is the very reason for obtaining wire-like and nano-rods $\mathrm{SnO}_{2}$. The chain structures of PEG are the morphology-directors in the growth process of nanorods and wire-like $\mathrm{SnO}_{2}$. The high-resolution TEM (HRTEM) morphology of an individual wire is shown in figure 4, which reveals that the wire is single crystal.

To determine the absorption band edge, we fit the absorption data to equation (1) for the $\mathrm{SnO}_{2}$ sample with PEG6000 added in the fabrication routes:

$$
(\alpha \hbar \omega)^{2} \propto\left(\hbar \omega-E_{\mathrm{g}}\right)
$$

in which $\hbar \omega$ is the photon energy, $\alpha$ is absorption coefficient and $E_{\mathrm{g}}$ is the absorption band gap energy. $E_{\mathrm{g}}$ is given by extrapolating the linear regions to zero absorption. As determined in figure 5, the band gap energy is $3.56 \mathrm{eV}$, which is the same as that of the bulk $\mathrm{SnO}_{2}$ material.

PL spectrum is convenient to investigate the structure and defect or impurity levels [14]. Figure 6 shows the room temperature PL spectrum for the $\mathrm{SnO}_{2}$ sample with PEG6000 added in the fabrication routes. The excitation wavelength used for the PL measurements is $350 \mathrm{~nm}(3.54 \mathrm{eV})$. The PL spectrum shows a strong UV emission peak at $389 \mathrm{~nm}(3.188 \mathrm{eV})$ and a broad blue emission near $470 \mathrm{~nm}(2.638 \mathrm{eV})$. Since the excitation and emissions are both lower than the band gap of $\mathrm{SnO}_{2}\left(E_{\mathrm{g}}=3.56 \mathrm{eV}\right)$, the emissions cannot be assigned to the direct recombination of a conduction electron in the Sn $4 p$ band and a hole in the O $2 p$ valence band. This is similar to that reported by Gu et al [15]. The UV emission is widely reported in the literature [15-17]. Kim [16] reported a weak peak at $3.13 \mathrm{eV}$ emitted from undoped $\mathrm{SnO}_{2}$ at low temperature and room temperature, and they thought that the origin of the peak was related to defects or nano-crystal grains or to defect levels associated with oxygen vacancies or tin interstitials resulting from the nano-size of the $\mathrm{SnO}_{2}$ film. Thereafter, Jin [14] concluded that the PL peak at $3.1 \mathrm{eV}$ was related to the structural defects and the peak at $2.4 \mathrm{eV}$ was due to oxygen vacancies. Furthermore, Wang [17] reported that the oxygen vacancies do not play an important role in the origin of the UV emission at $3.16 \mathrm{eV}$ of $\mathrm{Sb}$ doped $\mathrm{SnO}_{2}$. As far as our samples are concerned, the $\mathrm{SnO}_{2}$ sample may have a large number of defects: vacancies of oxygen, vacancy clusters and local lattice disorder at the interface and interior
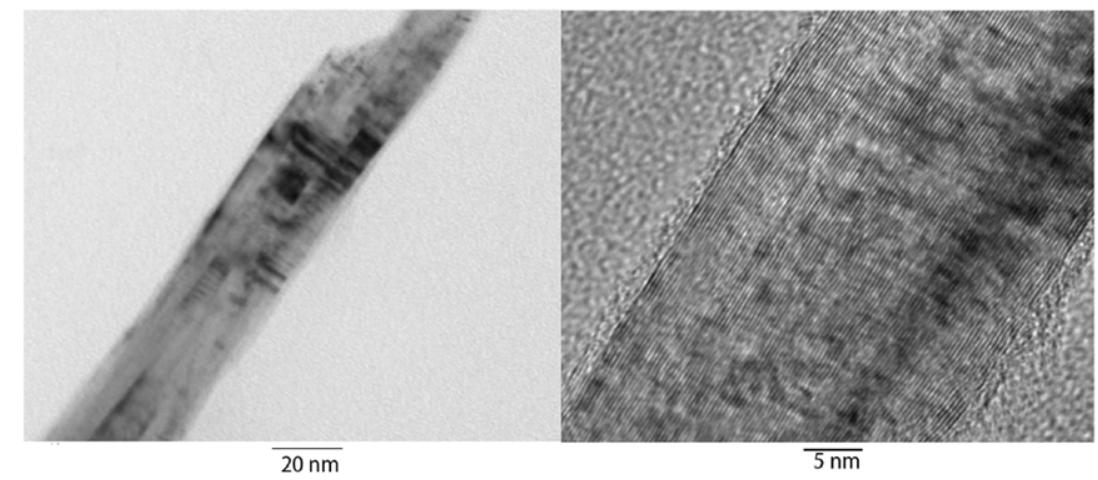

Figure 4. The HRTEM morphology of one individual $\mathrm{SnO}_{2}$ wire. 


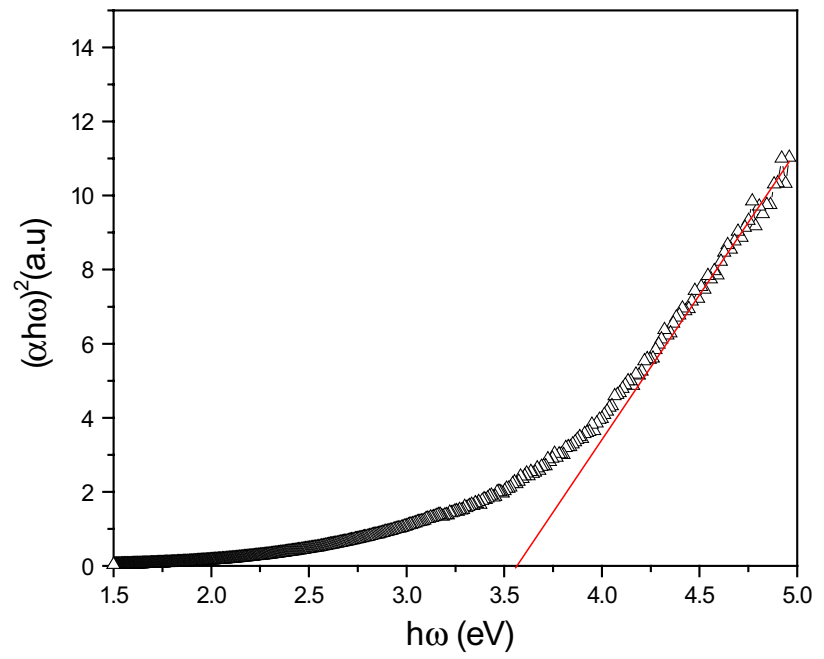

Figure 5. The $(\alpha \hbar \omega)^{2}$ as a function of $\hbar \omega-E_{\mathrm{g}}$ for $\mathrm{SnO}_{2}$ with PEG6000 added in the fabrication routes. The solid line is a linear fitting to the experimental data.

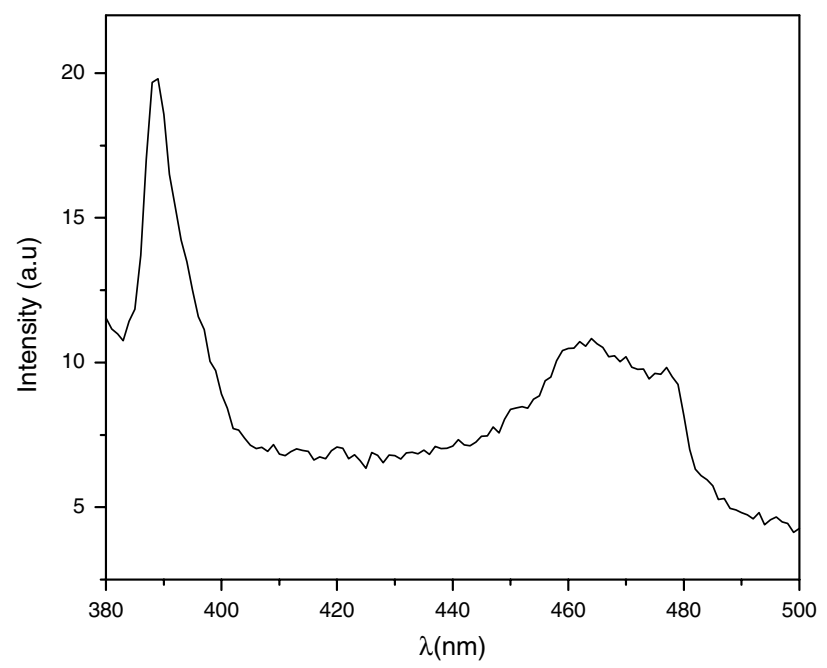

Figure 6. The PL spectra of $\mathrm{SnO}_{2}$ with PEG6000 added in the fabrication routes.

surface. So it is difficult to identify the origin of UV and blue emission.

\section{Conclusion}

In this paper we present a simple way of fabricating wire-like $\mathrm{SnO}_{2}$ at a low temperature of $350^{\circ} \mathrm{C}$. It is found that PEG plays a crucial role in this synthesis route. The chain structure of PEG is the morphology-director in the growth process. The band gap is determined to be $3.56 \mathrm{eV}$. There are two PL peaks at 389 and $470 \mathrm{~nm}$. Our synthesis method is different from the $\mathrm{V}-\mathrm{L}-\mathrm{S}$ process and promising.

\section{Acknowledgments}

This study was supported financially by the NSAF Joint Foundation of China (10376006) and by the Program for New Century Excellent Talents in University and the PhD Funding Support Program of the Education Ministry of China (20050614013).

\section{References}

[1] Nayral C, Viala E, Colliere V, Fau P, Senocq F, Maisonnat A and Chaudret B 2000 Appl. Surf. Sci. 164219

[2] Wang C, Appleby A J and Little F E 2002 Solid State Ion. 14713

[3] Ma Y-J, Zhou F, Lu L, Zhang Z 2004 Solid State Commun. 130 313

[4] Wang Z L and Pan Z 2002 Adv. Mater. 141029

[5] Pan Z W, Dai Z R and Wang Z L 2001 Science 2911947

[6] Wang Z L 2003 Adv. Mater 15432

[7] Dai Z R, Gole J L, Stout J D and Wang Z L 2002 J. Phys. Chem. B 1061274

[8] Dai Z R, Pan Z W and Wang Z L 2001 Solid State Commun. 118351

[9] Zhang J, Jiang F and Zhang L 2003 J. Phys. D: Appl. Phys. 36 L21

[10] Yu J, Liu S, Cheng B, Xiong J, Yu Y and Wang J 2006 Mater. Chem. Phys. 95206

[11] Liu X M and Zhou Y C 2004 J. Cryst. Growth 270527

[12] Ma X, Zhang Z, Wang X, Wang S, Xu F and Qian Y 2004 J. Cryst. Growth $\mathbf{2 6 3} 491$

[13] Liu J, Huang X, Duan J, Ai H and Tu P 2005 Mater. Lett. 59 3710

[14] Jin J, Seong P C, Cha I C, Dong C S and Jin S P 2003 Solid State Commun. 127595

[15] Gu F, Wang S F, Song C F, Lu M K, Qi Y X, Zhou G J, Xu D and Yuan D R 2003 Chem. Phys. Lett. 372451

[16] Kim T W, Lee D U and Yoon Y S 2000 J. Appl. Phys. 883759

[17] Wang Y H, Ma J, Ji F, Yu X H and Ma H L 2005 J. Lumin. 11471 